Gefässchirurgie 2016 · [Suppl 2]: 21:S71-S79 DOI 10.1007/s00772-016-0166-2

Published online: 13 July 2016

(c) The Author(s) 2016. This article is available at SpringerLink with Open Access.

CrossMark
T. Bisdas' · G. Torsello' - A. Stachmann' - R. T. Grundmann ${ }^{2,3}$ - CRITISCH study group

${ }^{1}$ Klinik für Vaskuläre und Endovaskuläre Chirurgie, Universitätsklinikum and St. Franziskus Hospital Münster, Münster, Germany

${ }^{2}$ Deutsches Institut für Gefäßmedizinische Gesundheitsforschung (DIGG) of the DGG, Berlin, Germany

${ }^{3}$ Wiss. Koordinator DIGG, Burghausen, Germany

\section{Results of peripheral bypass surgery in patients with critical limb ischemia (CRITISCH registry)}

CRITSCH study group: F. Adili, K. Balzer, T.Betz A. Billing, T. Bisdas, D. Böckler, D. Brixner, S.E. Debus, K.P. Donas, H.H. Eckstein, H.J. Florek, A. Gkremoutis, T. Hupp, T. Keck, J. Gerß, R.T. Grundmann, W. Klonek, W. Lang, U. Ludwig, B. May, A. Meyer, B. Mühling, A. Oberhuber, H. Reinecke, C. Reinhold, R.G. Ritter, H. Schelzig, C. Schlensack, T. Schmitz-Rixen, K.L. Schulte, M. Spohn, A. Stachmann, K. Stavroulakis, M. Steinbauer, M. Storck, G. Torsello, M. Trede, B. Weis-Müller, H. Wenk, T.Zeller, A.Zimmermann.

Supported by the German Institute for Vascular Healthcare Research (Deutsches Institut für Gefäßmedizinische Gesundheitsforschung, DIGG) of the German Society for Vascular Surgery and Vascular Medicine (Deutsche Gesellschaft für Gefäßchirurgie und Gefäßmedizin, DGG).

The German version of this article can be found under doi:10.1007/s00772-016-0116-z for 2003-2006 undergoing below-knee bypasses for CLI, 223 patients (18.2\%) received a prosthetic graft [2]. Of these bypasses $70 \%$ were to the popliteal artery and $30 \%$ to a more distal target. Patients receiving prosthetic grafts were treated for anticoagulation with warfarin more frequently $(57 \%)$ compared with those receiving vein bypasses $(24 \%)$. Following risk adjustment no significant differences in outcome were seen between prosthetic and vein bypasses (primary patency rate at 1 year $72 \%$ vs. $73 \%$ and major amputation rate $17 \%$ vs. $13 \%$, respectively), thus indicating the validity of the prosthetic bypass in the absence of a suitable vein and with appropriate anticoagulation. The present study examined the results of peripheral bypass surgery according to (a) the site of distal anastomosis and (b) the type of bypass material by analyzing the data of the CRITISCH registry $[3,4]$.

5/6 or Fontaine stage IV). Study endpoints were as follows:

Primary efficacy:

1. Amputation above the ankle of the index extremity or death from any cause, whichever occurred first.

Secondary endpoints:

1. Perioperative death within 30 days.

2. Major adverse limb event (MALE) in the index extremity at 1 and 2 years, such as amputation above the ankle or major intervention (new bypass, bypass revision (jump/interposition) or thrombectomy/thrombolysis).

3. Major adverse cardiovascular event (MACE): myocardial infarction, stroke or death from any cause.

4. Sustained clinical improvement at 2 years: upward shift on the Rutherford or Fontaine classification to the level of intermittent claudication in amputation-free surviving patients not requiring (primary improvement) or following (secondary improvement) repeat target lesion revascularization.

The methodology of the CRITISCH study has been described elsewhere [3,4]. A diagnosis of CLI symptoms of more than 2 weeks standing was the criterion for inclusion in the CRITISCH registry and CLI was defined as peripheral arterial occlusive disease and an ankle/brachial index of $\leq 0.4$ and/or residual pain (Rutherford class 4 or Fontaine stage III) and/or trophic disorders or necrosis/gangrene in the lower extremities (Rutherford classes

5. Any reintervention or amputation above the ankle in the index limb at 2 years, where reintervention was defined as any repeated vascular intervention in the index limb.

6. Any reintervention, amputation above the ankle in the index limb or stenosis/occlusion at 2 years.

7. Overall survival at 2 years.
Between January 2013 and September 2014 a total of 1200 CLI patients were 
Table 1 Patient characteristics of 284 patients receiving peripheral bypasses for critical limb ischemia

\begin{tabular}{|c|c|c|c|}
\hline Pre-existing diseases/risk factors & $\begin{array}{l}\text { Group } 1 \\
(n=75)\end{array}$ & $\begin{array}{l}\text { Group } 2 \\
(n=80)\end{array}$ & $\begin{array}{l}\text { Group } 3 \\
(n=129)\end{array}$ \\
\hline Number of men (\%) & $52(69.3)$ & $47(58.8)$ & $93(72.1)$ \\
\hline Number of women (\%) & $23(30.7)$ & $33(41.2)$ & $36(27.9)$ \\
\hline Patient age (years, mean/min-max) & $71.6(35-91)$ & $71.9(51-95)$ & $71.8(45-90)$ \\
\hline Age of females (years, mean/min-max) & $73.1(35-88)$ & $77.2(54-95)$ & $76.9(49-90)$ \\
\hline Age of males (years, mean/min-max) & $70.8(51-91)$ & $68.1(51-85)$ & $69.8(45-89)$ \\
\hline Patients aged over 80 years, $n(\%)$ & $17(22.7)$ & $22(27.5)$ & $27(20.9)$ \\
\hline Angina/coronary heart disease, $n(\%)$ & $33(44.0)$ & $35(43.8)$ & $50(38.8)$ \\
\hline $\begin{array}{l}\text { History of myocardial infarction } \\
\text { (<6 months), } n \text { (\%) }\end{array}$ & $4(5.3)$ & $8(10.0)$ & $5(3.9)$ \\
\hline History of stroke/TIA, $n(\%)$ & $11(14.7)$ & $9(11.3)$ & $11(8.5)$ \\
\hline Smokers (current), $n(\%)$ & $27(36.0)$ & $25(31.3)$ & $37(28.7)$ \\
\hline Diabetes mellitus, $n$ (\%) & $36(48.0)$ & $30(37.5)$ & $70(54.3)$ \\
\hline Obesity $\left(\mathrm{BMI}>30 \mathrm{~kg} / \mathrm{m}^{2}\right), n(\%)$ & $10(13.3)$ & $13(16.3)$ & $17(13.2)$ \\
\hline GFR $15-29 \mathrm{ml} / \mathrm{min} / 1.73 \mathrm{~m}^{2}, n(\%)$ & $10(13.3)$ & $4(5)$ & $3(2.3)$ \\
\hline GFR $<15 \mathrm{ml} / \mathrm{min} / 1.73 \mathrm{~m}^{2}$ or dialysis, $n(\%)$ & $3(4)$ & $3(3.8)$ & $7(5.4)$ \\
\hline Previous vascular procedure, $n(\%)$ & $27(36.0)$ & $36(45)$ & $76(58.9)$ \\
\hline PREVENT III (PIII) CLI risk score $\leq 3, n(\%)$ & $35(46.6)$ & $38(47.5)$ & $62(48.1)$ \\
\hline PREVENT III (PIII) CLI risk score 4-7, n (\%) & $37(49.4)$ & $39(48.7)$ & $62(48.1)$ \\
\hline PREVENT III (PIII) CLI risk score $\geq 8, n(\%)$ & $3(4.0)$ & $3(3.8)$ & $5(3.8)$ \\
\hline
\end{tabular}

$B M I$ body mass index, $C L I$ critical limb ischemia, GFR glomerular filtration rate, $T I A$ transient ischemic attack

Table 2 Rutherford classification of critical limb ischemia, peripheral run-off vessels and vein grafts used in groups $1-3$

\begin{tabular}{|llll}
\hline & $\begin{array}{l}\text { Group 1 } \\
(\boldsymbol{n}=\mathbf{7 5})\end{array}$ & $\begin{array}{l}\text { Group 2 } \\
(\boldsymbol{n}=\mathbf{8 0})\end{array}$ & $\begin{array}{l}\text { Group 3 } \\
(\boldsymbol{n}=\mathbf{1 2 9})\end{array}$ \\
\hline Rutherford classification & & & \\
\hline Class 4, $n$ (\%) & $17(22.7)$ & $26(32.5)$ & $29(22.5)$ \\
\hline Class 5, $n$ (\%) & $39(52.0)$ & $36(45.0)$ & $65(50.4)$ \\
\hline Class 6, $n$ (\%) & $19(25.3)$ & $18(22.5)$ & $35(27.1)$ \\
\hline Run-off, vessels open, $n(\%)$ & & & \\
\hline $0, n(\%)$ & $9(12.0)$ & $3(3.7)$ & $19(14.7)$ \\
\hline $1, n(\%)$ & $20(26.7)$ & $29(36.3)$ & $85(65.9)$ \\
\hline $2, n(\%)$ & $27(36.0)$ & $34(42.5)$ & $15(11.6)$ \\
\hline $3, n(\%)$ & $19(25.3)$ & $14(17.5)$ & $10(7.8)$ \\
\hline Vein graft, $n$ (\%) & $27(36)$ & $46(57.5)$ & $86(66.7)$ \\
\hline
\end{tabular}

prospectively included in the registry and 284 underwent peripheral bypass surgery. Of these 284 patients 75 underwent above-knee bypasses (group 1), 80 below-knee bypasses (group 2) and $129 \mathrm{crural} /$ pedal bypasses (group 3). A total of 159 vein bypasses were performed compared with 125 synthetic bypasses. Autologous vein bypasses in groups 1,2 and 3 were carried out in $36 \%$, $57.5 \%$ and $66.7 \%$, respectively. The total patient population comprised 192 males and 92 females. Tables 1 and 2 provide patient age and gender, comorbidities and baseline findings for the three groups.

- Table 1 also provides the modified PREVENT III (PIII) CLI risk score, designed to predict long-term outcome of infrainguinal vascular reconstruction in CLI patients $[5,6]$. Points were assigned to each patient as follows: dialysis 4 points, tissue loss 3 points, age $\geq 75$ years 2 points and coronary artery disease 1 point. The total number of points yields a score on the basis of which patients were stratified into risk categories as low risk (score $\leq 3$ ), medium risk (score 4-7) and high risk (score $\geq 8$ ).

\section{Statistical analysis}

The present study was a planned subgroup analysis of the CRITISCH study. Statistical analysis was performed using MedCalc statistical software (version 12.4.0.0, Ostend, Belgium). Descriptive statistics are presented for categorical variables as absolute numbers and percentages and continuous parameters as median (max-min interval). Categorical variables were compared using the $\chi^{2}$-test. In a first step, differences in complications between groups were compared. Analysis between patients with and without complications was performed with respect to the effect of the various prospectively recorded risk factors. Complications included the parameters wound infection, lymphatic fistula, compartment syndrome, acute coronary event, stroke/ transient ischemic attack (TIA) and major amputation. Amputation-free survival, freedom from amputation, survival and freedom from reinterventions were calculated and plotted using Kaplan-Meier curves. The rates of the abovementioned results were compared between groups using the log-rank test and calculated descriptively for each risk factor. The hazard ratio was presented with a $95 \%$ confidence interval. Differences with $p$-values $<0.05$ were considered statistically significant.

\section{Results}

\section{Perioperative results}

- Tables 3 and 4 show the perioperative results. Looking at the total patient population the procedure was without complications in 191 out of 284 patients (67.3\%) and bypasses were open at the time of hospital discharge in 236 out of 284 patients $(83.1 \%)$. No significant differences were observed between the three groups, although the results in 
Gefässchirurgie 2016 · [Suppl 2]: 21:S71-S79 DOI 10.1007/s00772-016-0166-2

(c) The Author(s) 2016. This article is available at SpringerLink with Open Access.

\section{T. Bisdas · G. Torsello · A. Stachmann · R. T. Grundmann · CRITISCH study group}

\section{Results of peripheral bypass surgery in patients with critical limb ischemia (CRITISCH registry)}

\section{Abstract}

Aim. On the basis of the CRITISCH registry outcomes in patients with critical limb ischemia (CLI) undergoing lower extremity bypass surgery were analyzed according to the site of distal anastomosis and type of bypass material.

Patients and methods. A total of 284 patients with lower extremity bypasses consisting of 75 patients with bypasses above the knee (group 1), 80 with bypasses below the knee (group 2) and 129 crural or pedal bypasses (group 3) were included in the study. Altogether, 159 autologous saphenous vein grafts and 125 synthetic grafts were used. Results. There were no perioperative complications in 191 out of the 284 patients
(67.3\%) and 236 of the 284 patients (83.1\%) had open bypasses at hospital discharge. An uneventful postoperative course was observed in $76 \%$ of the patients in group 1 , $62.5 \%$ in group 2 and $65.1 \%$ in group 3 .

Amputation-free survival was $86 \%$ at 1 year in group 1, $65 \%$ in group 2 and $69 \%$ in group 3. For bypasses above the knee synthetic grafts were at least not inferior to vein grafts (amputation-free survival at 1 year: prosthetic bypasses $92 \%$ and saphenous vein grafts $71 \%, p=0.147$ ), whereas in the crural/pedal bypass group vein grafts showed better amputation-free survival at 1 year $(76 \%)$ compared with synthetic bypasses $(56 \%, p=$ 0.105). Patients with a PREVENT III (PIII) CLI risk score $\leq 3$ exhibited better amputationfree survival at 1 year (78\%) compared to patients with a PIII CLI risk score of 4-7 (69\%, $p=0.053)$. The same applied to patients with Rutherford class 4 vs. Rutherford class $6 \mathrm{CLI}$. Conclusion. In patients with CLI and aboveknee bypasses, vein grafts confer no benefits compared with synthetic grafts for at least 1 year follow-up; however, in the case of more distal anastomoses vein grafts should be preferred.

Keywords

Critical limb ischemia - Bypass surgery · Autologous vein · Prosthetic graft · Amputationfree survival

\section{Ergebnisse der peripheren Bypasschirurgie bei Patienten mit kritischer Extremitätenischäme (CRITISCH-Register)}

Zusammenfassung

Zielsetzung. Die Ergebnisse der peripheren Bypasschirurgie in Abhängigkeit von der Lokalisation des distalen Anschlusses und von der Art des Bypassmaterials werden anhand der Daten des CRITISCH-Registers bei Patienten mit kritischer Extremitätenischämie (CLI) dargestellt.

Patienten und Methodik. Insgesamt 284 CLI-Patienten mit peripherem Bypass (75 Patienten mit Bypässen oberhalb des Knies [Gruppe 1], 80 Patienten mit Bypässen unterhalb des Knies [Gruppe 2] und 129 krurale/pedale Bypässe [Gruppe 3]) wurden analysiert. 159 Venenbypässe standen 125 Kunststoffbypässen gegenüber. Ergebnisse. Im Gesamtkrankengut verlief der Eingriff bei 191 von 284 Patienten
(67,3\%) ohne Komplikationen, bei 236 von 284 (83,1 \%) Patienten war der Bypass bei Entlassung offen. $76 \%$ der Patienten in Gruppe 1, 62,5\% in Gruppe 2 und $65,1 \%$ in Gruppe 3 zeigten einen komplikationslosen postoperativen Verlauf. Das amputationsfreie Überleben betrug nach 1 Jahr $86 \%$ in Gruppe 1, $65 \%$ in Gruppe 2 und $69 \%$ in Gruppe 3. Bei Bypässen oberhalb des Kniegelenks war Kunststoffmaterial dem Venenbypass zumindest nicht unterlegen (amputationsfreies Überleben nach 1 Jahr: Kunststoffbypass $92 \%$, Venenbypass $71 \%, p=$ 0,147 ), während umgekehrt in der Gruppe der kruralen/pedalen Bypässe Venenbypässe mit $76 \%$ ein besseres amputationsfreies Überleben nach 1 Jahr zeigten als Kunststoffbypässe mit $56 \%(p=0,105)$. Patienten mit einem PREVENT-III(PIII)-CLI-Risikokscore $\leq 3$ wiesen mit $78 \%$ ein besseres amputationsfreies Überleben nach 1 Jahr auf als Patienten mit PIII-CLI-Risikoscore 4-7 (69\%; $p=0,053$ ). Das Gleiche galt für Patienten mit Stadium 4 vs. Stadium 6 nach Rutherford.

Schlussfolgerung. Bei Patienten mit CLI im Follow-up über 1 Jahr bietet es keine Vorteile für Bypässe mit Anschlüssen oberhalb des Knies, Venen statt Kunststoffimplantate zu verwenden, wohl aber bei weiter distal gelegenen Anastomosen.

\section{Schlüsselwörter}

Kritische Extremitätenischämie - Bypasschirurgie - Autologe Vene - Gefäßprothese . Amputationsfreies Überleben group 1 showed a more favorable trend compared with the other groups. This was based on the greater proportion of patients with a complication-free postoperative course in group $1(76.0 \%)$ vs. groups 2 and $3(62.5 \%$ and $65.1 \%$, respectively, $p=0.076)$, the lower number of reinterventions as well as major and in particular, minor amputations and lastly, the approximately 3-day shorter period of hospitalization (- Table 3 ).

- Table 4 shows complication-free courses and graft patency rates at dis- charge according to potential risk factors for the total patient population. Differences were seen for Rutherford class 6 (54.2\% complication-free) vs. Rutherford class 4 (83.3\% complication-free, $p=0.0003)$, no open run-off vessel (61.3\% complication-free) vs. three open run-off vessels (76.7\% complication-free, $p=0.239)$, PIII CLI risk score $\geq 8$ (63.6\% complication-free) vs. PIII CLI risk score $\leq 3$ (73.3\% complicationfree, $p=0.732)$ and for diabetics $(61.0 \%$ complication-free) vs. non-diabetics
(73.0 \% complication-free, $p=0.044)$. In terms of graft patency rates at the time of discharge, the greatest differences were seen between Rutherford class 6 (69.4\% open) vs. Rutherford class $4(88.9 \%$ open, $p=0.008$ ) and run-off vessels (no detectable run-off vessel vs. one run-off vessel, bypass open in $64.5 \%$ vs. $85.8 \%$ of cases, $p=0.012$ ). 


\section{Originalien}

Table 3 Postoperative morbidity and mortality in the study groups

\begin{tabular}{|llll}
\hline & $\begin{array}{l}\text { Group 1 } \\
(\boldsymbol{n}=\mathbf{7 5})\end{array}$ & $\begin{array}{l}\text { Group 2 } \\
(\boldsymbol{n}=\mathbf{8 0})\end{array}$ & $\begin{array}{l}\text { Group 3 } \\
(\boldsymbol{n}=\mathbf{1 2 9})\end{array}$ \\
\hline Patients with no complications, $n$ (\%) & $57(76.0)$ & $50(62.5)$ & $84(65.1)$ \\
\hline Males with no complications, $n$ (\%) & $39 / 52(75.0)$ & $30 / 47(63.8)$ & $57 / 93(61.3)$ \\
\hline Females with no complications, $n$ (\%) & $18 / 23(78.3)$ & $20 / 33(60.6)$ & $27 / 36(75.0)$ \\
\hline Bypass open at discharge, $n$ (\%) & $65(86.6)$ & $67(83.8)$ & $104(80.6)$ \\
\hline Wound infection, $n$ (\%) & $9(12.0)$ & $8(10.0)$ & $14(10.9)$ \\
\hline Lymphatic fistula, $n$ (\%) & $4(5.3)$ & $7(8.8)$ & $10(7.8)$ \\
\hline Compartment syndrome, $n$ (\%) & $1(1.3)$ & $1(1.3)$ & $3(2.3)$ \\
\hline Reinterventions, $n$ (\%) & $8(10.7)$ & $7(8.8)$ & $22(19.0)$ \\
\hline Acute coronary event, $n$ (\%) & 0 & $3(3.8)$ & $4(3.1)$ \\
\hline Stroke/TIA, $n$ (\%) & $1(1.3)$ & 0 & 0 \\
\hline Major amputation, $n$ (\%) & $1(1.3)$ & $3(3.6)$ & $6(4.7)$ \\
\hline Minor amputation, $n$ (\%) & $7(9.3)$ & $12(15)$ & $20(15.5)$ \\
\hline Death, $n$ (\%) & $1(1.3)$ & $3(3.8)$ & $21.7(5-63)$ \\
\hline $\begin{array}{l}\text { Duration of hospitalization, days } \\
\text { (mean/min-max) }\end{array}$ & $18.9(5-65)$ & $21.5(6-93)$ & \\
\hline $\begin{array}{l}\text { TIA transient ischemic attack } \\
\text { The parameters wound infection, lymphatic fistula, compartment syndrome, acute coronary event, } \\
\text { stroke/TIA, major amputation and death are included under the term complications }\end{array}$ \\
\hline
\end{tabular}

Table 4 Postoperative outcome according to CLI category, run-off and other risk factors

\begin{tabular}{|c|c|c|}
\hline & $\begin{array}{l}\text { Patients without } \\
\text { complications }\end{array}$ & $\begin{array}{l}\text { Bypass open at dis- } \\
\text { charge }\end{array}$ \\
\hline Males, $n(\%)$ & $126 / 192(65.6)$ & 159/192 (82.8) \\
\hline Females, $n(\%)$ & $65 / 92(70.7)$ & 77/92 (83.7) \\
\hline Patients aged over 80 years, $n$ (\%) & $44 / 66(66.7)$ & $57 / 66(86.4)$ \\
\hline Patients aged less than 80 years, $n$ (\%) & $147 / 218(67.4)$ & $179 / 218(82.1)$ \\
\hline Rutherford class $4, n(\%)$ & $60 / 72(83.3)$ & $64 / 72(88.9)$ \\
\hline Rutherford class 5, $n$ (\%) & $92 / 140(65.7)$ & $122 / 140(87.1)$ \\
\hline Rutherford class 6, $n$ (\%) & $39 / 72(54.2)$ & $50 / 72(69.4)$ \\
\hline \multicolumn{3}{|l|}{ Run-off, vessels open } \\
\hline $0, n(\%)$ & $19 / 31(61.3)$ & $20 / 31(64.5)$ \\
\hline $1, n(\%)$ & $91 / 134(67.9)$ & $115 / 134(85.8)$ \\
\hline $2, n(\%)$ & $48 / 76(63.2)$ & $66 / 76(86.8)$ \\
\hline $3, n(\%)$ & $33 / 43(76.7)$ & $35 / 43(81.4)$ \\
\hline PIII CLI risk score $\leq 3, n(\%)$ & $99 / 135(73.3)$ & $117 / 135(86.7)$ \\
\hline PIII CLI risk score 4-7, n (\%) & $85 / 138(61.6)$ & $110 / 138(79.7)$ \\
\hline PIII CLI risk score $\geq 8, n(\%)$ & $7 / 11(63.6)$ & 9/11 (81.8) \\
\hline Diabetics, $n(\%)$ & $83 / 136(61.0)$ & $113 / 136(83.1)$ \\
\hline Non-diabetics, $n(\%)$ & $108 / 148(73.0)$ & $123 / 148(83.1)$ \\
\hline Obesity (BMI >30 kg/m²), $n(\%)$ & $26 / 40(65.0)$ & $30 / 40(75.0)$ \\
\hline $\mathrm{BMI}<30 \mathrm{~kg} / \mathrm{m}^{2}, n(\%)$ & $165 / 244(67.6)$ & $206 / 244(84.4)$ \\
\hline \multicolumn{3}{|l|}{ Previous vascular procedure } \\
\hline Yes, $n(\%)$ & $89 / 139(64.0)$ & $112 / 139(80.6)$ \\
\hline No, $n(\%)$ & $102 / 145(70.3)$ & $124 / 145(85.5)$ \\
\hline Vein graft, $n(\%)$ & $112 / 159(70.4)$ & $134 / 159(84.3)$ \\
\hline Prosthetic graft, $n(\%)$ & $79 / 125(63.2)$ & $102 / 125(81.6)$ \\
\hline
\end{tabular}

BMI body mass index, PIII CLI PREVENT III critical limb ischemia

\section{Follow-up results}

- Table 5 provides the follow-up results for the three groups. At $86 \%$, amputation-free survival at 1 year was significantly $(p=0.029)$ better in group 1 compared with group $2(65 \%)$ and group 3 $(69 \%)$. There were no differences in terms of reinterventions.

- Table 6 shows the results according to the bypass material used (i.e. vein vs. prosthetic graft). In the vein graft group, there were no differences in amputationfree survival at 1 year according to the site of distal anastomosis, whereas 1-year results for the prosthetic grafts were significantly better in group 1 at $92 \%(p=$ 0.002 ) compared with group 2 (amputation-free survival $54 \%$ ) and group 3 (56\%). In the above-knee bypasses, synthetic material was at least not inferior to vein bypasses (amputation-free survival: prosthetic graft $92 \%$, vein graft $71 \%, p=0.147$ ), whereas in the crural/ pedal bypasses, vein grafts showed better amputation-free survival at 1 year $(76 \%)$ compared with prosthetic grafts (56\%); however, even this difference was not statistically significant $(p=0.105)$. This statement and calculation ( $p$-value 0.105 ) relates to the comparison of all vein grafts, i.e. upper extremity, great saphenous vein (GSV) and small saphenous vein with all prosthetic grafts, e.g. Dacron and polytetrafluoroethylene (PTFE). If GSV bypasses are compared only with PTFE prosthetic bypasses (• Fig. 1), significantly better amputation-free survival can be observed for the former compared with the latter $(p=0.009)$ in the case of distal anastomoses.

- Table 7 provides a break-down of the follow-up results according to a number of risk factors. Patients in Rutherford stage 4 exhibited significantly better amputation-free survival at 1 year $(78 \%)$ compared with Rutherford stage 6 patients $(61 \%, p=0.045)$. The differences in 1-year results according to PIII CLI risk score were also significant (PIII CLI risk score $\leq 3$ : amputation-free survival $78 \%$ vs. PIII CLI risk score 4-7: amputation-free survival $69 \%, p=0.053$ ). The least favorable results were seen in the 11 patients with PIII CLI risk score $\geq 8$, who exhibited an amputation-free sur- 


\begin{tabular}{|c|c|c|c|}
\hline & $\begin{array}{l}\text { Group } 1 \\
(n= \\
75)\end{array}$ & $\begin{array}{l}\text { Group } 2 \\
(n= \\
80)\end{array}$ & $\begin{array}{l}\text { Group } 3 \\
(n= \\
129)\end{array}$ \\
\hline \multicolumn{4}{|c|}{ Amputation-free survival (\%) } \\
\hline At 6 months & 93 & 77 & 80 \\
\hline At 12 months & 86 & 65 & 69 \\
\hline \multicolumn{4}{|c|}{ Freedom from amputation (\%) } \\
\hline At 6 months & 98 & 90 & 85 \\
\hline At 12 months & 94 & 80 & 81 \\
\hline \multicolumn{4}{|l|}{ Survival (\%) } \\
\hline At 6 months & 95 & 85 & 92 \\
\hline At 12 months & 92 & 76 & 85 \\
\hline \multicolumn{4}{|c|}{ Freedom from reintervention (\%) } \\
\hline At 6 months & 78 & 78 & 74 \\
\hline At 12 months & 70 & 71 & 69 \\
\hline
\end{tabular}

vival of only $50 \%$ at 1 year $(p=0.076)$. One striking feature was that there were no significant differences in 1-year results $(p=0.693)$ regardless of whether no or three vessels were open (1-year amputation-free survival $74 \%$ vs. $78 \%$ ) or whether diabetes was present or not (1-year amputation-free survival $69 \%$ vs. $75 \%, p=0.486)$. Previous vascular interventions had no statistically significant effect on the results (1-year amputationfree survival $68 \%$ vs. $77 \%$ in the case of no previous intervention, $p=0.124$ ).

\section{Discussion}

The Vascular Study Group of New England database includes 2110 bypasses for CLI for the period 2003-2009 [7]. The mean patient age was 69.9 years, 5 years older than the mean age of the 797 claudication patients studied simultaneously. Some $24.7 \%$ of CLI patients received a prosthetic graft. While hospital mortality was low $(2.1 \%)$ reoperations were required in $15 \%$ of cases and wound infections were observed in $5.6 \%$ of patients. During the 1-year follow-up period $13.6 \%$ of the patients died and the major amputation rate was $12.2 \%$. The primary graft patency rate was $66.4 \%$ and the secondary patency rate was $77.4 \%$. Thus, the results for CLI were significantly less favorable compared with the intermittent claudication (IC) patients also investigated in the study. In the IC

\begin{tabular}{|c|c|c|c|}
\hline & $\begin{array}{l}\text { Group } 1 \\
(n= \\
75)\end{array}$ & $\begin{array}{l}\text { Group } 2 \\
(n= \\
\mathbf{8 0})\end{array}$ & $\begin{array}{l}\text { Group } 3 \\
(n= \\
129)\end{array}$ \\
\hline Vein graft, $n$ & 27 & 46 & 86 \\
\hline \multicolumn{4}{|c|}{ Amputation-free survival (\%) } \\
\hline At 6 months & 89 & 83 & 83 \\
\hline At 1 year & 71 & 72 & 76 \\
\hline \multicolumn{4}{|c|}{ Freedom from intervention (\%) } \\
\hline At 6 months & 81 & 74 & 80 \\
\hline At 1 year & 61 & 67 & 74 \\
\hline $\begin{array}{l}\text { Prosthetic } \\
\text { graft, } n\end{array}$ & 48 & 34 & 43 \\
\hline \multicolumn{4}{|c|}{ Amputation-free survival (\%) } \\
\hline At 6 months & 92 & 69 & 74 \\
\hline At 1 year & 92 & 54 & 56 \\
\hline \multicolumn{4}{|c|}{ Freedom from intervention (\%) } \\
\hline At 6 months & 75 & 85 & 61 \\
\hline At 1 year & 72 & 79 & 61 \\
\hline
\end{tabular}

group 1-year mortality was only $3.7 \%$, the major amputation rate $1.6 \%$, primary graft patency $78.9 \%$ and secondary patency $89 \%$ at 1 year. These results underline the impact of the baseline situation on the results of peripheral bypass surgery. As patients with CLI and IC have widely differing prognoses, the two groups need to be considered separately; this also applies to perioperative results. For CLI patients in the US nationwide inpatient sample (NIS), Sachs et al. [8] reported a hospital mortality of $2.6 \%$ and a major amputation rate of $3.9 \%$ following open bypass surgery, which is consistent with the results obtained in this study (hospital mortality in the total patient population for all bypasses $2.8 \%$ and major amputation rate $3.5 \%$ ). Furthermore, the analysis conducted by Sachs et al. [8] showed the amputation rate to crucially depend on the stage of CLI. Patients with rest pain or ulcers exhibited a perioperative amputation rate following bypass surgery of only $1.0 \%$ and $0.7 \%$, respectively, whereas a rate of $9.1 \%$ was observed in patients with gangrene. We distinguished CLI according to the Rutherford categories. Patients with Rutherford grade 4 exhibited significantly fewer postoperative complications (complication rate $16.7 \%$ ) compared with Rutherford grade 6 patients
(45.8 \%) and only $69.4 \%$ of bypasses were open on discharge in Rutherford grade 6 patients compared with $88.9 \%$ in Rutherford grade 4 patients ( $\bullet$ Table 4$)$, which was also a statistically significant difference. Similarly, run-off status had a significant effect on the immediate postoperative outcome: if no vessel was open, a graft patency rate of $64.5 \%$ was seen at patient discharge, compared with $85.5 \%$ in the case of run-off from at least one vessel. Similarly, an analysis of results performed by Hiramori et al. [9] of endovascular treatment for femoropopliteal lesions indicated that having any run-off at all is the key to a better outcome: the quality of the run-off is important, not the number of open vessels; however, it must be said that at 1-year follow-up, amputation-free survival in the present study did not differ according to whether run-off was present at baseline or not ( $\bullet$ Table 7).

It is important to pose the question in this context as to whether previous ipsilateral vascular interventions had a negative impact on results. This was not the case as far as the immediate postoperative result was concerned: the graft patency rate in the present patient population on discharge was $80.6 \%$ (previous vascular intervention) and $85.5 \%$ (no previous vascular intervention); however, better amputation-free survival was seen at 1 year in those patients who had not undergone previous vascular interventions (77\% vs. $68 \%$ ). This result shows a trend towards being consistent with observations in the Vascular Study Group of New England registry for 2003-2009 in this respect [10]. In that particular study, no immediate postoperative differences following infrainguinal bypasses were seen between patients with and without previous vascular interventions; however, the major amputation rate at 1 year among patients with previous endovascular interventions was significantly higher at $31 \%$ compared with patients without previous ipsilateral revascularization (20\%). This observation has not been confirmed by others. Santo et al. [11] described the long-term outcome of 314 peripheral autologous vein bypasses $(60 \%$ infrapopliteal) in CLI patients. The 30-day mortality rate was $3.5 \%$ and 5 -year outcomes were primary patency rate $45 \%$, 


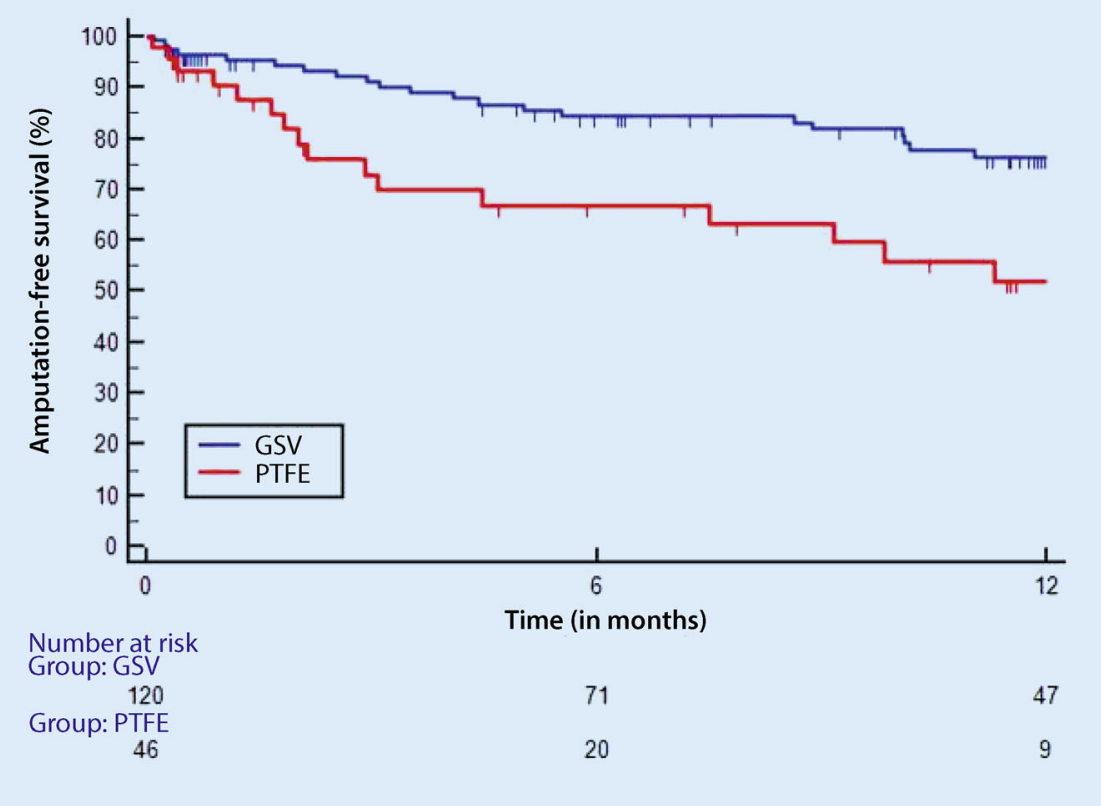

Fig. $1 \Delta$ Amputation-free survival in CLI patients with vein grafts (great saphenous vein, GSV) vs. polytetrafluoroethylene (PTFE) grafts. Only bypasses with distal anastomoses below the knee. Hazard ratio (HR) $2.27,95 \%$ confidence interval (CI) 1.08-4.75, $p=0.009$

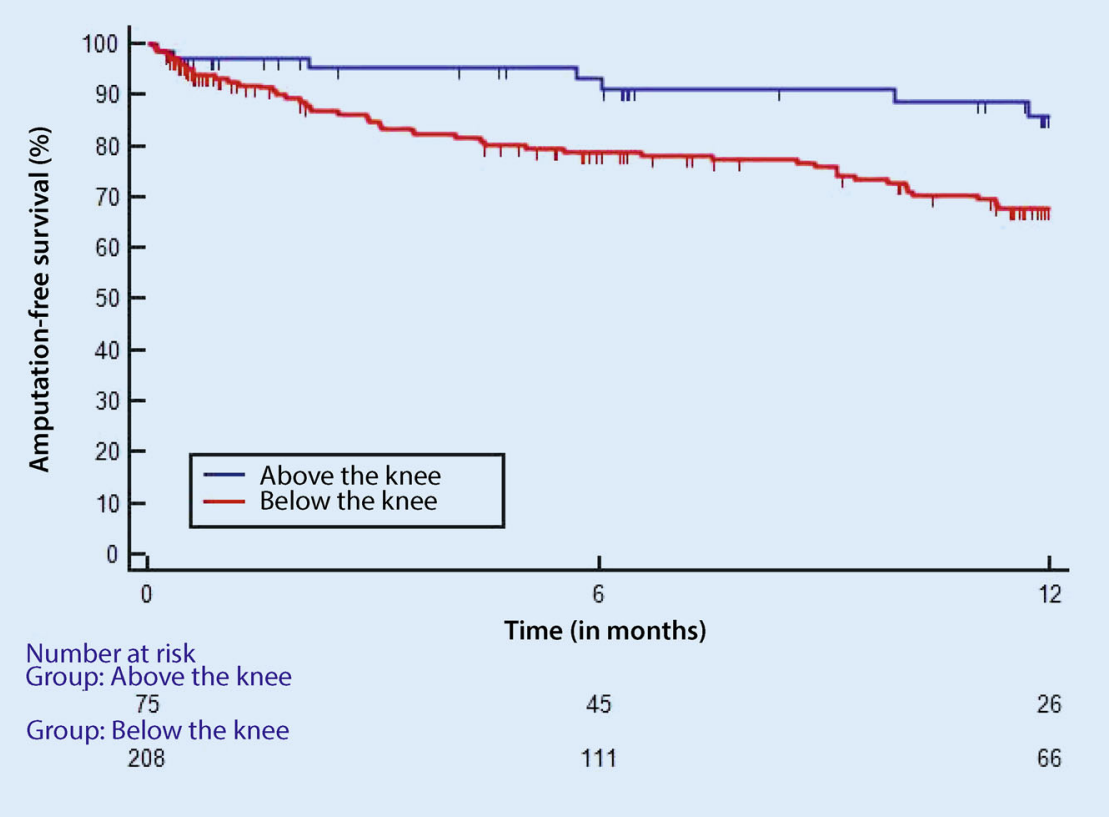

Fig. $2 \Delta$ Amputation-free survival in CLI patients with bypasses above and below the knee (including crural and pedal targets). Hazard ratio (HR) 2.80, $95 \%$ confidence interval (CI) $1.58-4.96, p=0.008$. GSV great saphenous vein, PTFE polytetrafluoroethylene

secondary patency rate $64 \%$, limb salvage $89 \%$ and amputation-free survival $49 \%$. No significant differences in outcome were seen according to whether patients had undergone previous endovascular interventions or not. It should be emphasized, however, that the 37 patients in the BASIL trial who received a bypass after initially failed angioplasty had a significantly worse amputation-free survival $(p=0.006)$ and somewhat worse overall survival (not significant) compared with the 184 bypass surgery-first patients [12].
This study determined the PREVENT III (PIII) CLI risk score, a stratification model designed to estimate amputation-free survival in CLI and infrainguinal bypass surgery patients. As - Table 4 shows, the PIII CLI risk score correlates only partially with the postoperative complication rate and although patients in the lowest score group had fewer complications compared with the others, this difference was not significant. There were also no differences in graft patency rates in the three risk groups on discharge; however, the lower the PIII CLI risk score, the better the amputation-free survival at 1-year follow-up (-Table 7). Mc Phee et al. [13] analyzed 30-day unplanned readmission following peripheral bypass surgery in 1543 patients, $84.5 \%$ of whom had CLI. Readmission, among other factors, was significantly related to the level of the distal anastomosis (e.g. popliteal, crural or pedal) and the lower the anastomosis, the more frequent readmissions were. In turn, the readmission rate correlated long-term with the amputation rate. These results provide evidence that the outcome of peripheral bypass surgery depends on the level of peripheral anastomosis. This was also demonstrated by Suckow et al. [2]. Patients receiving a vein bypass to the popliteal artery below the knee showed a primary graft patency rate of $78 \%$ (prosthetic graft $74 \%$ ). Outcomes of bypasses targeting crural/pedal vessels were significantly less favorable (vein graft patency rate $62 \%$ and prosthetic graft $66 \%$ ). What was striking in this study was that there were no significant differences between vein and prosthetic grafts in terms of primary patency at 1 year; however, the major amputation rate when the popliteal artery was the target and a prosthetic graft was used was worse (15\%) compared with when a vein graft was used (8\%); however, in the case of more distal crural/pedal anastomosis, there were no differences in major amputation rates between vein and prosthetic grafts (major amputation rate at 1 year for prosthetic grafts $19 \%$ and for vein graft, $14 \%)$. In our own patient population, freedom from amputation and hence also amputation-free survival 
Table 7 Follow-up outcomes according to CLI category, run-off and other risk factors

\section{Amputation-free sur- Amputation-free sur-} vival (\%) at 6 months vival (\%) at 1 year

\begin{tabular}{|c|c|c|}
\hline Rutherford class $4, n=72$ & 91 & 78 \\
\hline Rutherford class $5, n=140$ & 78 & 74 \\
\hline Rutherford class $6, n=72$ & 80 & 61 \\
\hline \multicolumn{3}{|l|}{ Run-off, vessels open } \\
\hline $0, n=31$ & 81 & 74 \\
\hline $1, n=134$ & 78 & 68 \\
\hline $2, n=76$ & 91 & 80 \\
\hline $3, n=43$ & 83 & 78 \\
\hline PIII CLI risk score $\leq 3, n=135$ & 88 & 78 \\
\hline PIII CLI risk score 4-7, $n=138$ & 78 & 69 \\
\hline PIII CLI risk score $\geq 8, n=11$ & 75 & 50 \\
\hline Diabetics, $n=136$ & 81 & 69 \\
\hline Non-diabetics, $n=148$ & 85 & 75 \\
\hline Obesity $\left(\mathrm{BMI}>30 \mathrm{~kg} / \mathrm{m}^{2}\right), n=40$ & 81 & 72 \\
\hline $\mathrm{BMI}<30 \mathrm{~kg} / \mathrm{m}^{2}, n=244$ & 82 & 76 \\
\hline \multicolumn{3}{|l|}{ Previous vascular procedure } \\
\hline Yes, $n=139$ & 79 & 68 \\
\hline No, $n=145$ & 86 & 77 \\
\hline Vein graft, $n=159$ & 84 & 74 \\
\hline Prosthetic graft, $n=125$ & 80 & 70 \\
\hline
\end{tabular}

$B M I$ body mass index, PIII CLI PREVENT III critical limb ischemia

(• Fig. 2) at 12 months, was significantly higher if the graft target was above the knee compared with below-knee targets; however, this statement is only valid if, as shown in - Fig. 2, no distinction is made between the type of graft material. Indeed, no difference was seen between the vein graft groups, whereas amputation-free survival at 1 year among patients receiving prosthetic grafts to suprapopliteal targets was $92 \%$ and to infrapopliteal and crural targets $54 \%$ and $56 \%$, respectively (•Table 6 ).

Vein grafts with infrapopliteal and crural targets therefore showed better outcomes than prosthetic grafts (• Fig. 1). This is consistent with observations made in the retrospective analysis performed by Uhl et al. [14], who saw a primary patency rate of $68.2 \%$ in the vein group and only $34.1 \%$ in the heparin-bonded PTFE graft group at 3 years. The limb salvage rate was $81.8 \%$ in the vein group vs. $56.5 \%$ in the heparin-bonded PTFE graft group and patient survival was $62.8 \%$ vs. $46.7 \%$, respectively. Neville et al. [15] also performed a retrospective comparison of heparin-bonded PTFE grafts $(n=62)$ and vein grafts $(n=50)$. Tibial artery bypasses were performed with heparin-PTFE grafts anastomosed using an autologous vein patch. The indication for surgery was CLI in the vast majority of cases $(91.9 \%$ in the PTFE group and $90 \%$ in the vein group). At $86 \%$, the 1-year primary vein graft patency rate was superior to that of PTFE grafts $(75.4 \%)$; however, there were no significant differences between the two groups in terms of amputation rates.

Some of the differences reported in the literature in results obtained from the comparison of vein vs. prosthetic grafts may be based on the fact that one study compared PTFE grafts and one study heparin-bonded PTFE grafts with vein grafts. Dorigo et al. [16] retrospectively evaluated results from an Italian multicenter registry and compared data on 180 below-knee bypasses using heparinbonded PTFE prosthetic grafts in diabetic CLI patients with 133 autologous vein grafts for the same indication. They reported 30-day bypass patency rates for the 2 groups of $92.2 \%$ and $93.2 \%$, respectively. Estimated patient survival rates at 48 months were $76.6 \%$ (heparin-PTFE) vs. $72.7 \%$ (vein). The primary graft patency rate was significantly better in the vein group (63.5\%) compared with the heparin-bonded PTFEgraft group (46.3\%). Differences in secondary graft patency ( $69.6 \%$ vs. $57.5 \%)$, limb salvage ( $82.4 \%$ vs. $75.4 \%)$, and amputation-free survival (64.4 \% vs. $59.9 \%$ ) between vein and heparin-bonded PTFE grafts were not significant. Gessaroli et al. [17] undertook a comparison of vein vs. heparin-bonded grafts in a total of 74 femorocrural bypasses. This study found no differences in primary patency rates between the two graft materials ( $84 \%$ for both groups) and the same applied to limb salvage rates (heparinPTFE $87 \%$ and vein $84 \%$ ) and 1-year patient survival ( $87 \%$ for both groups). Finally, Avgerinos et al. [18] reported on the retrospective analysis of a collective comprising a total of 407 infrainguinal bypasses including 116 popliteal (29\%), 226 tibial (56\%) and 65 pedal (16\%). Of these bypasses $96 \%$ were in CLI patients whereby GSV grafts were performed in $63 \%(n=255)$, alternative autologous vein grafts (upper extremity veins and composite vein segments) in $26 \%$ (106) and prosthetic grafts in $11 \%(n=47)$, of which 41 were heparin-bonded PTFE grafts. They reported a primary patency rate at 2 years of $47 \%$ for the GSV bypasses, $24 \%$ for the alternative veins and $43 \%$ for the prosthetic bypasses. Secondary patency at 2 years was calculated at $75 \%, 57 \%$ and $46 \%$, respectively, for the three groups. In this particular investigation, using GSV was significantly superior in terms of secondary patency compared with the other materials used; however, there was no significant difference between the alternative vein grafts and prosthetic grafts. The 2-year limb salvage rates were $86 \%, 78 \%$ and $72 \%$, respectively. These differences were not statistically significant. The key message of this investigation was that in the absence of the GSV as bypass material, complex reconstruction with alternative autologous vein grafts confers no advantages over heparin-bonded PTFE prosthetic grafts in below-knee bypasses. It should be noted that no distinction was 
made in our study between PTFE grafts with and without heparin bonding.

The present study had a number oflimitations: study design was a retrospective analysis of prospectively recorded data, the study was not randomized and the number of patients in each group was small. In this respect it is not possible to exclude a type II statistical error in the analysis of the different endpoints between groups as well as in the subgroup analysis. The statistically significant differences should be considered with caution. Clinical evaluations of patients as well as angiographic and duplex ultrasound results were analyzed by the attending physician and the data entered in the registry. There was no core laboratory or adverse event committee. This registry reflects the results of the 27 participating centers; however, these are not necessarily representative of the situation in all vascular centers in Germany. Furthermore, it should be noted from a critical perspective that the results of revascularization also depend on anticoagulation and antiplatelet therapy. The present study was not able to analyze concomitant medication over time.

\section{Conclusion}

- The present investigation demonstrated a trend, albeit not a statistically significant one, towards fewer complications in the immediate postoperative course in CLI patients treated with above-knee bypasses compared with more distal bypass targets. The same applied (with statistical significance) to Rutherford class 4 vs. Rutherford class 6 patients and to non-diabetics compared with diabetics. The greatest differences in terms of graft patency rates at the time of discharge were seen between Rutherford class 6 (69.4\% open) vs. Rutherford class 4 (88.9\% open) and run-off (no run-off vessel vs. one runoff vessel detected: bypass open in $64.5 \%$ vs. $85.8 \%$ of cases).

- At 1-year follow-up, amputationfree survival was significantly better in patients with above-knee bypasses compared to bypasses with more distal targets; in patients with
Rutherford class 4 vs. Rutherford class 6; and in patients with a PIII CLI risk score $\leq \mathbf{3}$ vs. a PIII CLI risk score of 4-7 ( $p=0.053)$.

- No differences were seen in amputation-free survival at 1 year according to the site of distal anastomosis in the vein graft group, whereas 1-year outcomes for prosthetic bypasses were significantly better when targets were suprapopliteal compared with infrapopliteal and crural bypasses.

- In patients receiving above-knee bypasses, prosthetic grafts were at least not inferior to vein grafts, whereas in the group receiving crural or pedal bypasses, GSV grafts showed better amputation-free survival at 1 year compared with prosthetic grafts.

\section{Corresponding address}

Prof. Dr. R. T. Grundmann

Wiss. Koordinator DIGG

In den Grüben 144, 84489 Burghausen,

Germany

grundmann@medsachverstand.de

\section{Compliance with ethical guidelines}

Conflict of interest. T. Bisdas, G. Torsello, A. Stachmann, R.T. Grundmann and the members of the CRITISCH study group state that they have competing interests. The supplement containing this article is not sponsored by industry.

The supplement containing this article is not sponsored by industry.

All studies on humans described in this manuscript were carried out with the approval of the responsible ethics committee and in accordance with national law and the Helsinki Declaration of 1975 (in its current revised form). Informed consent was obtained from all patients included in the study.

Open Access. This article is distributed under the terms of the Creative Commons Attribution 4.0 International License (http://creativecommons.org/ licenses/by/4.0/), which permits unrestricted use, distribution, and reproduction in any medium, provided you give appropriate credit to the original author(s) and the source, provide a link to the Creative Commons license, and indicate if changes were made.

\section{References}

1. Anderson JL, Halperin JL, Albert NM et al (2013) Management of patients with peripheral artery disease (compilation of 2005 and 2011 ACCF/AHA guideline recommendations): a report of the American College of Cardiology Foundation/ American Heart Association Task Force on practice guidelines. Circulation 127:1425-1443

2. Suckow BD, Kraiss LW, Stone DH, Schanzer A Bertges DJ, Baril DT, Cronenwett JL, Goodney PP, Vascular Study Group of New England (2013) Comparison of graft patency, limb salvage, and antithrombotic therapy between prosthetic and autogenous below-knee bypass for critical limb ischemia. Ann Vasc Surg 27:1134-1145

3. Bisdas T, Stachmann A, Weiss K, Borowski M, Grundmann RT, Torsello G (2014) Nationales Register für die Erstlinientherapiestrategien bei Patienten mit kritischer Extremitätenischämie (CRITISCH-Register): Studiendesign und aktueller Stand. Gefasschirurgie 19:135-140

4. Bisdas T, Borowski M, Torsello G, First-Line Treatments in Patients with Critical Limb Ischemia (CRITISCH) Collaborators (2015) Current practice of first-line treatment strategies in patients with critical limb ischemia. J Vasc Surg 62:965-973

5. Arvela E, Söderström M, Korhonen $M$, Halmesmäki $K$, Albäck A, Lepäntalo $M$, Venermo $M$, Biancari $F$ (2010) Finnvascscore and modified Prevent Ill score predict long-term outcome after infrainguinal surgical and endovascular revascularization for critical limb ischemia. JVasc Surg 52:1218-1225

6. Schanzer A, Goodney PP, Li Y, Eslami M, Cronenwett J, Messina L, Conte MS, Vascular Study Group of Northern New England (2009) Validation of the PIII CLI risk score for the prediction of amputationfree survival in patients undergoing infrainguinal autogenous vein bypass for critical limb ischemia. JVasc Surg 50:769-775

7. Simons JP, Schanzer A, Nolan BW, Stone DH, Kalish JA, Cronenwett JL, Goodney PP, Vascular Study Group of New England (2012) Outcomes and practice patterns in patients undergoing lower extremity bypass. JVasc Surg 55:1629-1636

8. Sachs T, Pomposelli F, Hamdan A, Wyers M, Schermerhorn M (2011) Trends in the national outcomes and costs for claudication and limb threatening ischemia: angioplasty vs bypass graft. JVasc Surg 54:1021-1031

9. Hiramori S, Soga Y, Tomoi Y, Tosaka A (2014) Impact of runoff grade after endovascular therapy for femoropopliteal lesions. JVasc Surg 59:720-727

10. Nolan BW, De Martino RR, Stone DH, Schanzer A, Goodney PP, Walsh DW, Cronenwett JL, Vascular Study Group of New England (2011) Prior failed ipsilateral percutaneous endovascular intervention in patients with critical limb ischemia predicts poor outcome after lower extremity bypass. JVasc Surg 54:730-735

11. Santo VJ, Dargon P, Azarbal AF, Liem TK, Mitchell EL, Landry GJ, Moneta GL (2014) Lower extremity autologous vein bypass for critical limb ischemia is not adversely affected by prior endovascular procedure. JVasc Surg 60:129-135

12. Bradbury AW, Adam DJ, Bell J, Forbes JF, Fowkes FG, Gillespie I, Ruckley CV, Raab GM, BASIL trial Participants (2010) Bypass versus Angioplasty in Severelschaemia of the Leg (BASIL) trial: Analysis of amputation free and overall survival by treatment received. JVasc Surg 51 (5 Suppl):18S-31S

13. McPhee JT, Barshes NR, Ho KJ, Madenci A, Ozaki CK, Nguyen LL, Belkin M (2013) Predictive factors of 30- 
day unplanned readmission after lower extremity bypass. J Vasc Surg 57:955-962

14. Uhl C, Hock C, Betz T, Greindl M, Töpel I, Steinbaue M (2015) Comparison of venous and HePTFE tibial and peroneal bypasses in critical limb ischemia patients unsuitable for endovascular revascularization. Vascular 23:607-613

15. Neville RF, Capone A, Amdur R, Lidsky M, Babrowicz J, Sidawy AN (2012) A comparison of tibial artery bypass performed with heparin-bonded expanded polytetrafluoroethylene and great saphenous vein to treat critical limb ischemia. J Vasc Surg 56:1008-1014

16. Dorigo W, Pulli R, Castelli P, Dorrucci V, Ferilli $F$, De Blasis G, Monaca V, Vecchiati E, Pratesi C, Propaten Italian Registry Group (2011) A multicenter comparison between autologous saphenous vein and heparin-bonded expanded polytetrafluoroethylene (ePTFE) graft in the treatment of critical limb ischemia in diabetics. J Vasc Surg 54:1332-1338

17. Gessaroli $M$, Tarantini $S$, Leone $M$, Fabbri $E$, Panzini I (2015) A comparison of femorocrural bypasses performed with modified heparinbonded expanded polytetrafluorethylene grafts and those with great saphenous vein grafts to treat critical limb ischemia. Ann Vasc Surg 29:1255-1264

18. Avgerinos ED, Sachdev U, Naddaf A, Doucet DR, Mohapatra A, Leers SA, Chaer RA, Makaroun MS (2015) Autologous alternative veins may not provide better outcomes than prosthetic conduits for below-knee bypass when great saphenous vein is unavailable. JVasc Surg 62:385-391 